\title{
Tipologia semântica das condicionais de se no Português de Moçambique ${ }^{1}$ Víctor Mércia Justino \\ Universidade Eduardo Mondlane
}

\begin{abstract}
:
This paper discusses the semantic typology of the conditionals of the Mozambican Portuguese (MP), focusing on the occurrence of verb tenses and mood, in comparison with European Portuguese (EP). Based on data collected through a combination of different research methods, the analysis suggests that the differences between MP and EP are limited: in both varieties, there are three semantic classes of the conditionals (factual, hypothetical and counterfactual) and the correlation between tense/mood and interpretation of conditionals is not necessarily biunivocal. However, there are some differences between MP and EP in contexts where tenses and mood are used in a more marked way in hypothetical and counterfactual conditionals. Moreover, other differences result from ambiguous EP input, and the fact that MP speakers use distinct grammatical rules: common to EP and particular rules of MP.
\end{abstract}

Keywords: conditionals, semantic interpretation, indicative tenses, subjunctive tenses

Palavras-chave: condicionais, valores semânticos, tempos do indicativo, tempos do conjuntivo

\section{Introdução}

O português de Moçambique (PM) é uma variedade do português, distinta do português europeu (PE), e, de acordo com os dados do Censo de 2007, falada por cerca de metade da população moçambicana, como L1 (10,7\%) ou como L2 (39,7 \%) (Chimbutane 2012). Para além do português, que é a língua oficial, são faladas, em Moçambique, mais de vinte línguas bantu.

O presente artigo tem como objetivos (i) descrever as condicionais de se do PM, no que se refere particularmente à sua tipologia semântica, com foco na distribuição dos tempos e modos verbais, e (ii) compará-las com as condicionais do PE descritas por Justino (2016) e Justino (em curso). Tal como no PE, na descrição semântica das condicionais do PM, assumiremos como ponto de partida a classificação tripartida das condicionais em factuais, hipotéticas e contrafactuais, relacionando esta tripartição com a distribuição dos tempos e modos verbais na oração condicional.

Este trabalho encontra-se estruturado como se segue: na secção 2, apresentam-se os dados e a metodologia de pesquisa; na secção 3, descrevem-se os diferentes valores semânticos das condicionais de se do PM e sua relação com os tempos e modos verbais; na secção 4, apresenta-se a síntese dos resultados da secção 3, mostrando em que aspetos o PM é semelhante ao PE e em que se distingue deste; finalmente, na secção 5, apresentam-se as considerações finais.

\footnotetext{
${ }^{1}$ Este trabalho foi desenvolvido no âmbito do meu projeto de tese de doutoramento, financiado pela Fundação Calouste Gulbenkian, que me concede a bolsa de estudos, bem como na qualidade de colaborador CLUL (UID/LIN/00214/2013) financiado pela Fundação para a Ciência e a Tecnologia. Agradeço os comentários e sugestões aos dois revisores anónimos do artigo e à audiência do XXXIII Encontro Nacional da APL, que se realizou na Universidade de Évora, de 27 a 29 de setembro de 2017.
} 


\section{Os dados linguísticos e a metodologia de pesquisa}

Em traços gerais, a situação do português em Moçambique é a de que esta língua é uma L2 para a maioria dos seus falantes. Uma consequência desta situação é a variabilidade maior dos traços gramaticais que caracterizam esta variedade relativamente àquela que se verifica em línguas adquiridas como L1 (Gonçalves 2010 e 2013). Segundo Gonçalves (2013: 161), esta variabilidade evidencia-se na maneira pouco regular e sistemática com que os traços se manifestam na produção linguística dos falantes moçambicanos. Posto isto, optou-se por dados empíricos obtidos através de metodologias híbridas (Larsen-Freeman \& Long 1991) ou abordagem multimétodos (Mönnink 1999). Dito de outra maneira, os dados empíricos do PM foram obtidos pela combinação de paradigmas de pesquisa de dois tipos: qualitativo (dados de observação) e quantitativo (dados experimentais, nomeadamente testes de elicitação), esperando, deste modo, fazer-se uma descrição mais consistente das condicionais de se do PM.

Os dados de observação foram extraídos de diferentes corpora eletrónicos, nomeadamente o subcorpus Moçambique do $\mathrm{CRPC}^{2}$, o corpus Moçambula do projeto $\mathrm{AC} \mathrm{DC}^{3}$ e o corpus África ${ }^{4}$, e não eletrónicos, o corpus de Justino (2011). Na tabela 1, apresenta-se o tipo de dados destes corpora, a dimensão dos mesmos, bem como o perfil sociolinguístico da população que os produziu, nos casos em que estas informações estão disponíveis: ${ }^{5}$

\begin{tabular}{|c|c|c|c|}
\hline \multicolumn{3}{|c|}{ CORPUS } & \multirow[b]{2}{*}{ Perfil sociolinguístico dos informantes } \\
\hline Fonte & Tipo & $\begin{array}{l}N^{\circ} \text { (aproximado) } \\
\text { de palavras }\end{array}$ & \\
\hline $\begin{array}{l}\text { CRPC } \\
\text { (Moçambique) }\end{array}$ & Escrito & 640.000 & $\begin{array}{l}\text { Vários níveis de instrução (primário, secundário e } \\
\text { universitário) / Português é L2 para a maioria }\end{array}$ \\
\hline Moçambula & Escrito & $58.000^{6}$ & $\begin{array}{l}\text { Vários níveis de instrução (secundário e } \\
\text { universitário) / Português é L2 para a maioria }\end{array}$ \\
\hline $\begin{array}{l}\text { África } \\
\text { (Moçambique) }\end{array}$ & Oral e escrito & 25.000 & $\begin{array}{l}\text { Vários níveis de instrução (primário, secundário e } \\
\text { universitário) / Português é L2 para a maioria }\end{array}$ \\
\hline Justino (2011) & Oral & 250.000 & $\begin{array}{l}\text { Vários níveis de instrução (primário, secundário e } \\
\text { universitário) / Português é L2 para a maioria }\end{array}$ \\
\hline
\end{tabular}

Tabela 1. Corpora do PM: tipo de dados, dimensão dos corpora e o perfil sociolinguístico da população que os produziu

Para a obtenção dos dados relevantes, recorreu-se à pesquisa de corpora por concordâncias, nos corpora eletrónicos. Quanto ao corpus não eletrónico (34 ficheiros de áudio), extraíram-se manualmente todas as ocorrências de condicionais de se. Do ponto de vista quantitativo, as condicionais apuradas nesses corpora são apresentadas na tabela 2:

\footnotetext{
2 Corpus de Referência do Português Contemporâneo disponível em: http://www.clul.ul.pt/en/research-teams/183-reference-corpusofcontemporary-portuguese-crpc

${ }^{3}$ Acesso a Corpora / Disponibilização de Corpora, disponível em: https://www.linguateca.pt/CETEMPublico/

${ }^{4}$ Disponível em: http://alfclul.clul.ul.pt/teitok/corpusafrica/index.php?action=cqp\&act=advanced

${ }^{5}$ Refira-se que os dados do PE que serviram de base para a comparação com os dados do PM são de corpora CETEMPúblico e CRPC (cf. Justino (2016) e Justino (em curso)). O CETEMPúblico, constituído apenas por dados escritos extraídos do jornal diário Público, contém 191.3 milhões de palavras e o CRPC, mais concretamente o subcorpus Portugal, contém mais de 300 milhões de palavras e abrange textos escritos (literário, jornalístico, técnico, etc.) e de registos orais (formal e informal).

${ }^{6}$ Palavras extraídas de 100 cartas de leitores publicadas, em 2012, em vários jornais moçambicanos.
} 


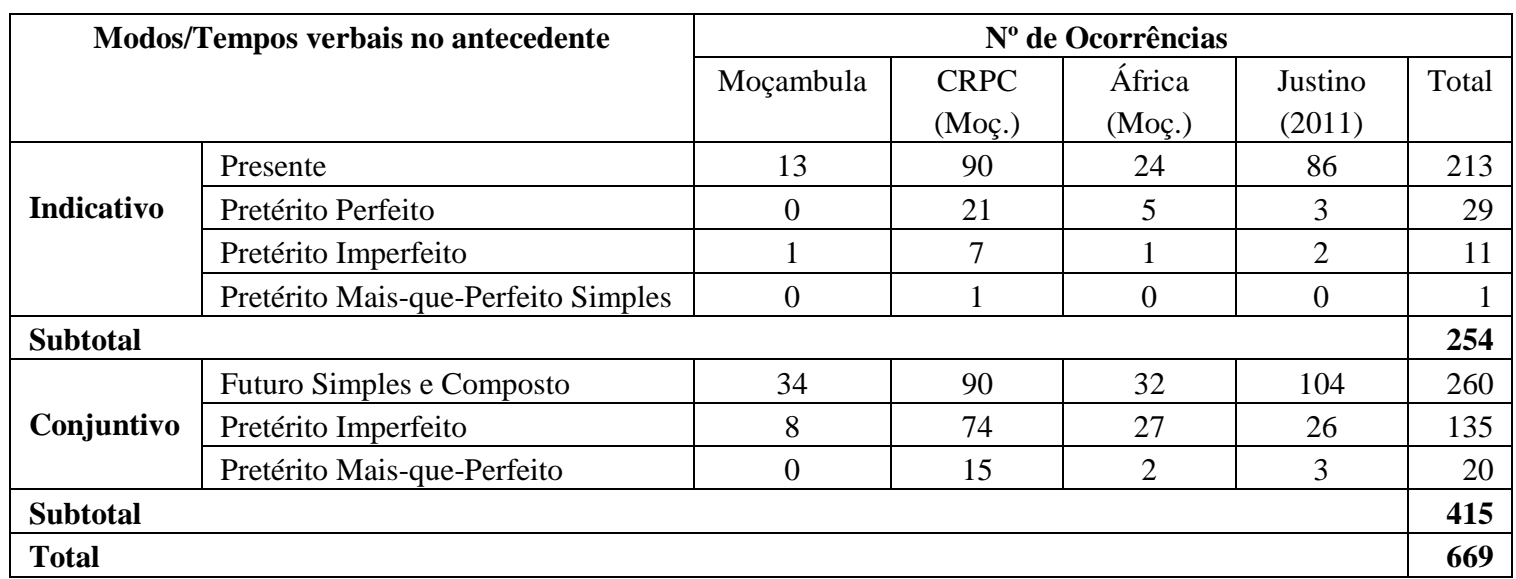

Tabela 2. Condicionais de se nos corpora do PM (Moçambula, CRPC, África e Justino 2011)

Para além destes dados de observação, recorreu-se, para efeitos deste estudo, a dados experimentais recolhidos através de testes de Produção Provocada (PP) e Juízo de Gramaticalidade (JG), por forma a alargar a base empírica, incluindo, por um lado, casos que ocorrem nos corpora de forma não representativa e que, por isso, poderiam não permitir caracterizar de forma consistente as estruturas alvo (estão, neste caso, por exemplo, as condicionais com o Pretérito Mais-que-Perfeito Simples, de que se regista apenas uma ocorrência, e com o Pretérito Imperfeito do Indicativo, com onze ocorrências (cf. a tabela 2)) e, por outro, estruturas que também são alvo de análise (e.g., condicionais genéricas universais, irónicas ou contrafactuais no modo indicativo) e que não ocorreram nos corpora do PM analisados.

As tarefas de PP são constituídas por dois testes. O primeiro, constituído por 12 frases-teste e 3 distratoras, consistia na elaboração de frases usando o verbo dado entre parênteses para preencher os espaços em branco (cf. anexo II). O segundo, constituído por 15 frases-teste, consistia em preencher os espaços em branco com uma forma adequada dos verbos apresentados entre parênteses (cf. também anexo II).

O teste de JG é constituído por 15 frases-teste e 5 distratoras. Neste teste, solicitou-se aos informantes os seus juízos de gramaticalidade relativamente às 20 frases (veja-se, no anexo II, o tipo de teste).

Os testes de elicitação foram aplicados, em 2015, a 25 sujeitos universitários moçambicanos (11 do sexo feminino; 14 do sexo masculino). A idade dos sujeitos variava entre os 19 e os 40 anos. A maioria deles tem o português como L2.

A opção por dados de diferentes tipos (orais e escritos; espontâneos, provocados e de juízo de gramaticalidade) ${ }^{7}$ produzidos por falantes do PM/L1 e L2, instruídos e não instruídos, permitiu captar diferenças, entre o PM e o PE, decorrentes da heterogeneidade dos dados e do nível de proficiência em português.

\footnotetext{
${ }^{7}$ Tem sido frequentemente notado que "a variação é desejável para que os resultados não sejam alterados pela homogeneidade do corpus" (Reis 2006:43).
} 


\section{Tipologia semântica das condicionais do PM}

\subsection{Condicionais factuais}

No PM, ocorrem condicionais factuais nas quais a situação descrita no antecedente se verifica no mundo real como um facto (Iatridou 1991, Marques 2001, Gomes 2008). Do exemplo (1a), depreende-se que $o$ locutor sabe (tem conhecimento de) que se caminha para a violência no desporto rei, e, de (1b), que eles estão a sofrer com o seu próprio dinheiro.

(1) a. Se nesse campo festivo que é o desporto rei marchamos para a violência, começo a pensar que estamos mais próximo de uma «Nação Pária» par=2

b. Como é que podemos desenvolver desta forma se sofremos com o nosso dinheiro? par=1

Enquanto condicionais em que o antecedente é tido como um facto no mundo real, estas estruturas podem ser parafraseadas por estruturas com operadores factivos (2), na linha de Gomes (2008).

(2) a. Já que nesse campo festivo que é o desporto rei marchamos para a violência, começo a pensar que estamos mais próximo de uma «Nação Pária».

b. Se os números apresentados foram confirmados, o Chissano ganha as eleições. (CRPC) (= Já que os números foram confirmados, o Chissano ganha (ganhou) as eleições).

No entanto, nem todas admitem este tipo de paráfrase, admitindo, porém, outros tipos, aproximáveis. Por

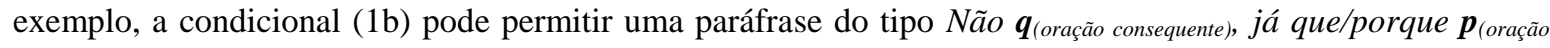
antecedente) (3a), pelo facto de a oração consequente, que ocorre em forma de uma interrogativa retórica, implicar uma expetativa que é contraditória ao facto nela expresso. As factuais como (3b), de nexo interproposional dedutivo, poderiam ser parafraseadas como em (3b').

(3) a. ₹ Não podemos desenvolver, já que/visto que temos estado a sofrer com o nosso dinheiro.

b. Se sabemos de tudo isso é porque existe uma língua em que nós somos falantes.

b'. É porque existe uma língua em que nós somos falantes que sabemos de tudo isso. ${ }^{8}$

Os dados revelam que, à leitura factual, está associado apenas o indicativo, quando o antecedente é assumido como um facto no mundo real, condicionais de leitura episódica (4). Daí que uma possível alternância com o conjuntivo pode gerar a agramaticalidade da condicional (5).

(4) a. Se nesse campo festivo que é o desporto rei marchamos para a violência, começo a pensar que estamos mais próximo de uma «Nação Pária» par=2

b. Se os números apresentados foram confirmados, o Chissano ganha as eleições. (CRPC)

\footnotetext{
${ }^{8}$ Note-se, a propósito das condicionais de nexo dedutivo, que as hipotéticas e contrafactuais, quanto a mim, parecem não admitir a paráfrase que se sugere para as condicionais que são factuais (3b):

i. a. Se soubermos de tudo isso é porque existe uma língua de que todos somos falantes.

a'. *É porque existe uma língua de que nós somos falantes que soubermos de tudo isso.

b. *Se tivéssemos sabido de tudo isso é porque existia uma língua de que todos somos falantes.

$\mathrm{b}^{\prime}$. *\#É porque existia uma língua de que todos somos falantes que tivéssemos sabido de tudo isso.

A leitura de b'é factual e não contrafactual como em b.
} 
(5) a. Se nesse campo festivo que é o desporto rei marchamos/\#marchemos/*marchássemos para a violência, começo a pensar que estamos mais próximo de uma «Nação Pária»

b. Se os números apresentados foram/\#tiverem sido/*tivessem sido confirmados, o Chissano ganhou as eleições.

Também nas condicionais do tipo genérico universal (Justino 2011 ou 2016), à leitura factual está associado apenas o indicativo (6). ${ }^{9}$ Nestes exemplos, o uso do Presente genérico indica que, no mundo real, no tempo da enunciação $\left(\mathrm{t}_{0}\right)$, como, aliás, em qualquer momento, o que é descrito no antecedente é um facto: o narciso é uma flor (6a) e o interlocutor é humano (6b).

(6) a. Se o narciso é uma flor, pertence ao reino vegetal. (PP)

b. Todos os humanos são mortais. Logo, se tu és humano, tu és mortal. (PP)

Por outro lado, existem condicionais factuais em que o que é um facto é o conteúdo da frase total (Brito 2003) ou a correlação entre o antecedente e o consequente:

(7) a. Se não vou correr nas manhãs, estou com um grupo de amigos. (JR41, Justino 2011)

b. Os pais sempre tinha que dizer alguma coisa se as coisas não correr bem. (Corpus África)

c. Portanto ali o gado às vezes perdia-se, se se perdesse, o pai tinha que nos mandar ir à procura. (CRPC)

Como estruturas que expressam uma correlação de eventos/situações (ou genéricas habituais, Norris 2003; Lopes 2009; Justino 2011, 2016), estas construções são equivalentes a frases temporais introduzidas por quando e sempre que (8). ${ }^{10}$

(8) a. Quando/Sempre que não vou correr nas manhãs, estou com um grupo de amigos.

b. Os pais sempre tinha que dizer alguma coisa quando as coisas não correr bem.

c. Portanto ali o gado às vezes perdia-se, quando se perdesse, o pai tinha que nos mandar ir à procura.

Nas factuais que decorrem da correlação de eventos/situações, tanto o indicativo (8a) como o conjuntivo (8b,c) são usados. Nas correlativas de eventos passados, o Pretérito Imperfeito do Indicativo e o Pretérito Imperfeito do Conjuntivo podem alternar entre si, mantendo-se sempre o indicativo (Pretérito Imperfeito), no consequente:

(9) Portanto ali o gado às vezes perdia-se, se/quando/sempre que se perdesse/perdia, o pai tinha que nos mandar ir à procura do tal gado ou cabrito.

\footnotetext{
9 As frases em (6) foram extraídas de um teste de PP. Para além do modo indicativo, os sujeitos produziram, para estas frases, condicionais no modo conjuntivo (incluindo em contextos em que o seu uso, tendo em conta o nosso conhecimento do mundo, não é o mais natural, do ponto de vista do PE cf. ?Todos os humanos são mortais. Logo, se tu fores/fosses humano, tu és/serias mortal.:

i. a. Se o narciso for/fosse uma flor, pertence/pertenceria ao reino vegetal. (PP)

b. Todos os humanos são mortais. Logo, se tu fores/ fosses humano, tu és/serias mortal. (PP)

Mas, o uso do conjuntivo induz outras interpretações do antecedente: hipotética ou contrafactual. Daí que se assume que, no PM, o indicativo é o modo deste subtipo de condicionais, quando associadas à leitura factual.

${ }^{10}$ Esta propriedade é atestada pelos dados naturais (de corpora), conforme ilustra o seguinte exemplo:

i. Passa muito tempo que este assunto não é abordado nos meios de comunicação social ou ainda se (quando) é abordado tem passado despercebido por muitas pessoas, incluindo os que comigo partilham o dia-a-dia. par=3
} 
Nas correlativas de eventos que se verificam em to, para além do Presente (10), pode usar-se o Futuro do Conjuntivo (11). ${ }^{11}$

(10) Hoje não se respeita o sexo e se uma menina atinge os vinte anos sem conhecer homem as amigas gozam-lhe e riem dela dizendo que é anormal. (CRPC)

(11) a. Alguns membros da comunidade participam com regularidade em todas actividades, outros apenas participam se houver dinheiro. (CRPC)

b. Se for preso sai logo no dia seguinte. Se demorar a sair agora até há bons advogados que aparecem logo a defender-nos. (CRPC)

O Futuro do Conjuntivo com valor aspetual de habitualidade parece poder permutar com o Presente do Indicativo, também de valor aspetual, mantendo-se o Presente habitual no consequente:

(12) a. Alguns membros da comunidade participam com regularidade em todas actividades, outros apenas participam sempre que houver/há dinheiro.

b. Se for preso sai logo no dia seguinte. Sempre que demorar/demora a sair agora até há bons advogados que aparecem logo a defender-nos.

Síntese sobre o tempo/modo nas condicionais factuais do PM:

$\checkmark$ Quando o antecedente é assumido como um facto do mundo real (factuais episódicas e genéricas universais), usa-se apenas o modo indicativo. Por isso, depreende-se que a correspondência entre o valor factual e o tempo/modo é direta nestas condicionais.

$\checkmark$ Nas condicionais de correlação de eventos, a factualidade é expressa pelos modos Indicativo e Conjuntivo. Nas correlativas de eventos no presente/atemporal, encontramos o Presente do Indicativo e o Futuro do Conjuntivo, no antecedente. Já nas correlativas de eventos passados, a factualidade é expressa pelo Pretérito Imperfeito do Indicativo ou pelo Pretérito Imperfeito do Conjuntivo, mas também se pode usar o Futuro do Conjuntivo como forma supletiva do Pretérito Imperfeito (cf. Os pais sempre tinha que dizer alguma coisa se as coisas não correr (= corressem) bem). Deste modo, conclui-se que, nas correlativas, a relação entre a factualidade e os tempos/modos verbais não é simples.

\subsection{Condicionais hipotéticas}

No PM, as condicionais hipotéticas são exemplificadas pelas frases em (13), nas quais a hipótese de o antecedente ser verdadeiro no futuro é deixada em aberto. Como tal, estas condicionais podem ser parafraseadas pelo operador caso, com sentido/valor hipotético, conforme mostram as frases apresentadas entre parênteses no fim de cada exemplo): ${ }^{12}$

\footnotetext{
${ }^{11}$ O Futuro do Conjuntivo usado é de valor aspetual de habitualidade e está atestado em outras construções:

i. Sempre que tiver tempo estou sempre ao lado de um rádio ou de gravador a escutar música. (CRPC)

12 Nestes contextos, o conector caso expressa um valor episódico, tal como se pode observar por não apresentar restrições de episodicidade:

i. Caso por ventura a pessoa entre um dia / esta tarde em contacto com o vírus, o organismo reagiria combatendo o HIV

Alguns exemplos de corpora do PM que atestam o uso de caso com sentido hipotético são:

i. Ao viajante, o Qurbán não é obrigatório, mas caso regresse à casa antes do pôr-do-sol do dia 12 de Dhul-Hidja, então deverá fazê-lo se para tal dispuser de meios materiais. par=2

ii. Depois de acontecer e caso não se cumpra com o prometido algo pode acontecer a pessoa que fez a promessa ou um membro familiar. par=1
} 
(13) a. Se o investimento externo continuar, Moçambique vai manter um crescimento sustentável. par=1 (= Caso o investimento externo continue, Moçambique vai manter um crescimento sustentável)

b. Todas estas colectividades e outras não mencionadas, sempre falaram das suas dificuldades financeiras e em certo sentido se caíssem ninguém seria colhido de surpresa. par=1 $(=\ldots$ caso caíssem ninguém seria colhido de surpresa.)

c. O tiro me ensurdeceu. Não ouvi, não vi. Se acertei, lhe cortei o fio da vida, isso ainda hoje me duvido. (CRPC) (= caso tenha acertado, lhe cortei o fio da vida.)

d. Salomão, se me voltas a falar assim, rebento-te as fuças. (Corpus África) (= Salomão, caso me voltes a falar assim, rebento-te as fuças.)

De acordo com os dados, ao valor hipotético estão associados tempos do conjuntivo (13a,b) e do indicativo (13c,d). Relativamente aos tempos do conjuntivo, note-se que o Futuro simples que ocorre nas hipotéticas é temporalmente localizado num intervalo de tempo futuro. Daí poder alternar com o Presente do Indicativo com o valor de futuro (14), mas não com o Presente habitual (15) que, como vimos, é possível quando o Futuro está associado à interpretação factual (veja-se os exemplos (12)).

(14) Os mufanas que já compraram gritam: Laurinda, tu vais mbunhar. E se mbunhares/ mbunhas teus filhos não vai comer nada. (CRPC)

(15) Os mufanas que já compraram gritam: Laurinda, tu vai mbunhar. *E se mbunhas sempre, teus filhos não vai comer nada. (= *E sempre que mbunhas, teus filhos não vai comer nada.)

O Pretérito Imperfeito do conjuntivo geralmente é hipotético quando se combina com predicados eventivos. No exemplo a seguir, com um predicado de evento, é fácil obter a interpretação em que a hipótese de todas as coletividades caírem no futuro é deixada em aberto (16a) e não podendo essa frase representar uma situação que não teve efetivamente lugar (contrafactual) ou que já teve lugar (factual) (16b):

(16) a. Todas estas colectividades e outras não mencionadas sempre falaram das suas dificuldades financeiras e em certo sentido se/ $\underline{\text { caso }}$ algum dia caíssem ninguém seria colhido de surpresa.

b. *Todas estas colectividades e outras não mencionadas sempre falaram das suas dificuldades financeiras e em certo sentido se/caso caíssem, mas não caíram/ e já caíram, ninguém seria colhido de surpresa.

Além disso, ao contrário do Pretérito Imperfeito com valor contrafactual (17a), quando é apenas hipotético, o Imperfeito dificilmente pode combinar-se com o Condicional Composto ou o Pretérito Mais-quePerfeito Composto (tipicamente associados à contrafactualidade) (17b):

(17) a. Injusto seria se alguém lhe apontasse o dedo. (CRPC) (Injusto teria sido se alguém lhe tivesse apontado o dedo).

b. ?*Todas estas colectividades (...) se caíssem, ninguém teria sido colhido de surpresa.

O Pretérito Imperfeito do Conjuntivo está igualmente associado à leitura hipotética nas frases que envolvem uma espécie de ato de fala diretivo indireto (18). De (18a), pode inferir-se que o enunciador sugere 
que o seu interlocutor apanhe o metro. ${ }^{13}$ Já a frase (18b) parece estar associada a algo mais forte do que uma mera sugestão/convite (talvez a uma ameaça). A ideia de recomendação de que o interlocutor não cometa um crime fica melhor se se tratar da segunda pessoa (cf. Se tu cometesses um crime, não te veremos mais). ${ }^{14}$

(18) a. Se apanhasses o metro já, chegarás a tempo. (PP)

b. Se ela cometesse um crime, não a veremos mais. (PP)

A par do conjuntivo, os tempos do indicativo são recorrentes nas condicionais hipotéticas:

(19) a. Se eu te levo para Lichinga, vais encontrar pessoas que falam português de maneiras diferentes. (NZC39, Justino 2011)

b. Se alguém me pergunta se me disser que a educação baixou ainda terá que me focalizar onde parte portanto para dizer que baixou a qualidade da educação. (Corpus África)

c. Não vendo atacado, mas se conseguia ter um dinheiro de vender atacado, ia vender. (LFJ51, Justino 2011)

Nestes exemplos, o que é hipótese em aberto é distante do que é esperado no contexto conversacional. Por isso, seria preferencial o uso do modo conjuntivo, do ponto de vista do PE. Do ponto de vista do PM, embora exemplos como os de (19) estejam atestados nos dados espontâneos, ao contrário de (19a), (19b,c) são, quanto a mim, marginais, por o Presente (19b) e o Pretérito Imperfeito do Indicativo (19c) terem sido usados com referência temporal futura. As minhas intuições foram confirmadas pelos juízos de gramaticalidade de estudantes universitários que as assinalaram como agramaticais, assumindo que nesses contextos o modo conjuntivo deveria ter sido selecionado. Isto vem corroborar a ideia de que, por um lado, os falantes do PM não partilham todos, entre si, os mesmos traços e regras gramaticais (Gonçalves 2010 ou 2016) e, por outro, que, na mente destes falantes, podem estar disponíveis duas gramáticas em concorrência, a referente ao PE e a referente ao PM. Repare-se que, em (19b), o sujeito hesita/alterna entre o uso do indicativo e do conjuntivo na mesma frase. São falantes com competências múltiplas (Lighfoot 2006).

\section{Síntese sobre o tempo/modo nas condicionais hipotéticas}

$\checkmark$ Às hipotéticas estão associados tempos do conjuntivo (Futuro e Pretérito Imperfeito) e do indicativo (Presente, Pretérito Perfeito, Pretérito Mais-que-Perfeito Simples e Pretérito Imperfeito - este apenas enquanto forma supletiva do Pretérito Imperfeito do Conjuntivo).

$\checkmark \quad$ Nas hipotéticas do PM, pode não haver distinção de interpretação associada ao uso do Indicativo e Conjuntivo, já que o primeiro, como o segundo, é usado em contextos que envolvem a consideração de hipóteses que são distantes do mundo real.

$\checkmark$ A relação entre o valor hipotético e o tempo/modo verbais é não direta/simples.

\footnotetext{
${ }^{13}$ No PM, em vez do Pretérito Imperfeito do Conjuntivo, pode-se usar o Presente do Indicativo para formular um convite ou uma sugestão:

i. Se apanhas o metro já, chegas a tempo. (PP)

${ }^{14}$ É notar que o PE não admite estas frases. Nesta variedade, e nestes contextos, a hipoteticidade é expressa como se segue:

i. a. Se apanhasses o metro já, chegavas a tempo.

b. Se ela cometesse um crime, não a veríamos mais.

ii. a. Se apanhares o metro já, chegarás/chegas a tempo.

b. Se ela cometer um crime, não a veremos/vemos mais.
} 


\subsection{Condicionais contrafactuais}

Nos dados considerados, as condicionais com interpretação contrafactual são como as frases (20), que pressupõem que o que é descrito no antecedente é falso (Lakoff 1970, von Fintel 2012, e.o.).

(20) a. Se eu tivesse feito exame, eu estou consciente que passava este curso. (CRPC)

b. Aquele homem é um fugista. Se não fosse era um fugista, ele havia de parar aqui. (CRPC)

c. Se tu és santo, eu sou o Papa. (PP)

Nas contrafactuais comuns/canónicas (20a,b), pode-se acrescentar à proposição antecedente a sua negação (21a) (Brito 2003) e se pode ser substituído por caso (21b) (Gomes 2008).

(21) a. Se eu tivesse feito exame, mas não fiz, eu estou consciente que passava este curso.

b. Caso eu tivesse feito o exame, mas não fiz, eu estou consciente que passava este curso.

As não comuns (e.g., as de sentido irónico) (20c), pelo contrário, não são coordenáveis com adversativas de polaridade inversa nem parafraseáveis com recurso a caso (22). ${ }^{15}$

(22) *Caso tu sejas santo, mas não és, eu sou o Papa.

Ainda nas condicionais contrafactuais não canónicas, sobressaem condicionais como as de (23), enfáticas, por sempre haver a repetição do verbo/predicado do antecedente no consequente (cf. ser cantor e cantar).

(23) a. Se Wazimbo não fosse cantor, seria cantor. par=2

b. Se não cantasse, $\underline{\text { cantava. }}$ par=2

O facto de, no consequente, ocorrer uma proposição que é contraditória do antecedente é tido como uma estratégia de tomar o consequente como o reforço da proposição descrita no antecedente: Wazimbo não seria outra coisa senão cantor (23a)/ Ele apenas cantava (23b).

Nas contrafactuais canónicas (24), bem como nas de sentido enfático (23), à leitura contrafactual está associado apenas o modo conjuntivo (Pretérito Imperfeito ou Pretérito Mais-que-Perfeito). ${ }^{16}$

(24) Nós chegámos aqui tarde. Se chegássemos logo em Fevereiro ou se tivéssemos chegado logo em Fevereiro, eu teria ido contactar do instituto de línguas para mudar-me de curso! (CRPC)

\footnotetext{
15 Nestas condicionais, o locutor basicamente expressa um comentário irónico face ao conteúdo do antecedente, que é tido como verdadeiro por outros interlocutores, conforme é a seguir demonstrado pelo contexto discursivo em que as irónicas do PM podem ocorrer: i. A: Eu sou santo.

B: Se tu és santo, então eu sou o Papa. (= não és santo./ De santo não tens nada.)

${ }^{16}$ Nas condicionais irónicas, o Presente do Indicativo é o tempo geralmente selecionado e o sentido irónico decorre da contestação ou negação do antecedente, comparando-o com o conteúdo da oração consequente, reconhecido pragmaticamente como falso (cf. ser santo vs ser Papa ou ser linda vs ser a miss universo):

i. Se tu és santo, então eu sou o Papa. (PP)

ii. Se tu és linda, eu sou a miss universo. (PP)
} 
As atestações com indicativo em condicionais contrafactuais, como (25), são vistas como agramaticais/marginais por falantes do PM culto. ${ }^{17}$

(25) Nós estaríamos muito felizes se podemos dispor de infra-estruturas que pudéssemos apenas reformar, disse Chissano. (CRPC)

Também contrafactuais que, no PE, são gramaticais com o indicativo (26) são agramaticais de acordo com os meus juízos de gramaticalidade, enquanto falante nativo do PM/L1, bem como de outros falantes cultos do PM/L1 ou L2 (estudantes universitários).

(26) a. *Se o Zé tem ido às aulas, não chumbava/teria chumbado no primeiro ano. (JG)

b. *Se ele marca o golo, teríamos ganho o jogo. (JG)

Por último, refira-se que a contrafactualidade pode igualmente ser expressa por fosse (que) + Pretérito Imperfeito do Indicativo do verbo principal, numa construção particular do PM, que não tem correspondência no PE:

(27) a. Aquele homem é um fugista. Se não fosse era um fugista, ele havia de parar aqui. (CRPC)

b. Eu estava naquela zona de museu então ela pensa que pode subir o preço mas aí é que está//não pode só se fosse que era mercado. (Corpus África)

Esta estratégia de expressão da contrafactualidade é recorrente nos dados de aquisição, exemplos (28), e nem sempre pode ocorrer na gramática adulta, chegando a ser considerada marginal, para além de ser de registo coloquial. Entretanto, a sua ocorrência na gramática adulta de certos falantes do PM, sobretudo os da subvariedade não educada, conforme atestam os dados de (27), indica que ela não foi abandonada, mas sim mantida como parte da Língua-I.

(28) a. Se fosse que era grande ia ser professora. (aluno do ensino primário)

b. Se fosse que tinha dinheiro ia comprar uma casa na cidade. (aluno do ensino primário)

\section{Síntese sobre o tempo/modo nas condicionais contrafactuais}

$\checkmark$ No PM, as condicionais contrafactuais podem ser canónicas, parafraseáveis com recurso a caso e coordenáveis com adversativas de polaridade inversa, e não canónicas, enfáticas e de sentido irónico, que não são parafraseáveis com recurso a caso e não são coordenáveis com adversativas de polaridade inversa.

$\checkmark$ Nas contrafactuais canónicas, bem como nas de sentido enfático, à leitura contrafactual está associado apenas o modo conjuntivo. Daí que, ao contrário das factuais e das hipotéticas, a correspondência entre o tempo/modo e a contrafactualidade seja direta.

$\checkmark$ Para se expressar a contrafactualidade, pode-se recorrer igualmente à forma 'fosse (que) + Pretérito Imperfeito do Indicativo do verbo principal'.

\footnotetext{
${ }^{17}$ Tomando como referência o PE padrão, as propriedades gramaticais do PM distribuem-se ao longo de um continuum polilectal, em que no extremo basilectal se encontram as subvariedades de falantes com baixa escolaridade e no extremo acrolectal a subvariedade educada/culta, mais próxima do PE, e falada maioritariamente pela população urbana com um nível de instrução mais elevado (cf. Gonçalves 2010). Refira-se que também no PE o conjuntivo seria obrigatório nesta frase. Os tempos do Indicativo que ocorrem, nas contrafactuais canónicas, são o Pretérito Perfeito Composto (26a) e o Presente do Indicativo (26b), sendo que o Presente ocorre em registo mais marcado: na oralidade (cf. Justino 2016).
} 
$\checkmark$ Nas condicionais irónicas, o Presente do Indicativo é o tempo geralmente selecionado e o sentido irónico decorre da contestação ou negação do antecedente, comparando-o com o conteúdo da oração consequente, reconhecido como falso.

\section{Condicionais do PM em comparação com as do PE}

$\mathrm{Na}$ secção anterior, procurámos descrever as condicionais do PM, com foco na distribuição do tempo/modo verbais. Nesta secção, iremos apresentar, em síntese, os resultados principais dessa descrição, referindo, em cada classe semântica, os aspetos em que o PM e o PE são semelhantes e aqueles em que o PM se distingue do PE.

\subsection{Condicionais factuais}

Tal como no PE, no PM, as condicionais factuais podem ser episódicas e correlativas de eventos/situações presentes ou passadas.

Nas episódicas, a leitura factual decorre do facto de o valor de verdade do antecedente ser dado como um facto do mundo real, como foi referido no ponto 3.1. Neste subtipo de factuais, usam-se apenas tempos no modo indicativo, tanto no antecedente como no consequente. Dito de outra forma, a factualidade numa condicional não correlativa/episódica é expressa apenas pelos tempos do indicativo. Deste modo, concluímos que a correspondência entre o valor factual e o tempo/modo é direta, nas factuais episódicas, o que aproxima o PM do PE e ambas as variedades do português do que é também assumido, para outras línguas, como o espanhol e o inglês (cf. Montolío 1999, Karttunner \& Peters 1979, Norris 2003).

Nas condicionais em que o que é um facto é a frase total, correlativas de eventos/situações, o PM e o PE são semelhantes por poderem usar, para além do indicativo, o conjuntivo, ainda que a literatura sobre as condicionais do PE não o tenha observado (provavelmente como resultado de não terem sido analisados dados de corpora; Brito 2003, Lobo 2013). Nas correlativas de eventos passados, tanto no PM como no PE, pode selecionar-se o Pretérito Imperfeito do Indicativo ou o Pretérito Imperfeito do Conjuntivo. Nestas factuais, estes tempos/modos verbais podem alternar entre si, mantendo-se sempre o Pretérito Imperfeito do Indicativo na oração principal (cf. Portanto ali o gado às vezes perdia-se, se se perdessel perdia o pai tinha que nos mandar ir à procura), para além de existir uma implicação temporo-aspetual que permite que se comute com quando ou sempre que. ${ }^{18}$

Tal como no PE, nas condicionais correlativas do PM, a identidade de tempos verbais (ou, simplesmente, concordância temporal) é obrigatória (29). Nestes exemplos, factuais de correlação de eventos passados, temos sempre o Pretérito Imperfeito do Indicativo/Conjuntivo + o Imperfeito do Indicativo, sendo ambos os tempos verbais usados com o valor temporal de passado em relação a t $\mathrm{t}_{0}$ e aspetual de habitualidade.

(29) a. Se entravámos às $7, \underline{\text { saíamos }} /{ }^{*} \underline{\text { saímos }} /{ }^{*} \underline{\text { sairemos }}$ às $12 \mathrm{~h}$.

b. Portanto ali o gado às vezes perdia-se, se se perdesse, o pai tinha/*teve que nos mandar ir à procura.

\footnotetext{
${ }^{18}$ Para o PE, eis um exemplo:

i. No final de 1997 era chique organizar uma festa perto de San José e depois enfiar os convidados numa carrinha e levá-los a passear no Mae. (CRPC) Se [= Quando/Sempre que] se pusesse isso no convite, as pessoas que compareciam à festa duplicavam.
} 
O PM distingue-se do PE, bem como das condicionais de outras línguas, como o português do Brasil (PB), o inglês ou o espanhol (Gomes 1998; Montolío 1999), por ainda poder usar o Futuro do Conjuntivo nas factuais correlativas de eventos passados (30a) e presentes/atemporais (30b).$^{19}$

(30) a. Os pais sempre tinha que dizer alguma coisa se as coisas não correr bem. (Corpus África) [se = sempre que/quando]

b. Alguns membros da comunidade participam com regularidade em todas actividades, outros apenas participam se houver dinheiro. (CRPC) $[\text { se }=\text { sempre que/quando }]^{20}$

Nas correlativas de eventos passados (30a), o Futuro do Conjuntivo é usado como forma supletiva do Pretérito Imperfeito do Indicativo/Conjuntivo (cf. Os pais sempre tinha que dizer alguma coisa se as coisas não corriam / corressem bem.), ao passo que, nas correlativas de eventos que se verificam em $\mathrm{t}_{0}$ (30b), permuta com o Presente habitual, mantendo-se o Presente do Indicativo (também habitual) na oração matriz (cf. Alguns membros da comunidade participam com regularidade em todas actividades, outros apenas participam se há dinheiro.). Deste modo, podemos assumir que o Futuro do Conjuntivo que ocorre nas factuais é de dimensão aspetual de habitualidade.

Uma outra propriedade das condicionais factuais do PM que as distingue das do PE tem a ver com o facto de, no PM, as correlativas de eventos poderem ser sempre parafraseáveis por estruturas com caso:

(31) a. Se não vou correr nas manhãs, estou com um grupo de amigos. (JR41, Justino 2011)

a'. Caso não vá correr nas manhãs, estou com um grupo de amigos.

b. Se entravámos às 7, saíamos às $12 \mathrm{~h}$. (NK 39, Justino 2011)

b’. Caso entrássemos às 7, saíamos às $12 \mathrm{~h}$.

No PE, as paráfrases (31), com caso, são agramaticais/marginais. ${ }^{21}$ Elas só seriam possíveis enquanto paráfrases de condicionais com valor episódico e não factuais, conforme é demonstrado pelos exemplos (32).

(32) a. Caso não vá correr, estarei com um grupo de amigos. (A partir de: Se não for correr, estarei com um grupo de amigos).

b. Caso entrássemos às 7 h, saíamos às 12. (A partir de: Se entrarmos às 7, saímos às $12 \mathrm{~h}$.)

Assim, ao contrário do PE e do PB (Gomes 2008), assumimos que, no PM, a conjunção caso pode encabeçar condicionais factuais. Isto significa que, no PM, para além de episódico, este operador pode ser correlativo. Repare-se que, nas condicionais do PM com valor correlativo, é possível caso coocorrer com

\footnotetext{
${ }^{19}$ No PE, o Futuro do Conjuntivo é sempre hipotético, mesmo quando usado em condicionais de correlação de eventos/situações, porque induz a leitura genérica de situações ancoradas no futuro.

i. Os cientistas acham que se este líquido que acabaram de misturar atingir 100 graus, entra em ebulição; vão verificar se assim é. [se = sempre que] (Telmo Móia, c.p.)

ii. Se a água atingir a temperatura de 100 graus, entrará/entra em ebulição (Sempre que/quando a água atingir a temperatura de 100 graus, entrarál *entra em ebulição).

${ }^{20}$ Esta frase é possível no PE, com leitura hipotética (ver ainda a nota anterior).

${ }^{21}$ Entretanto, Telmo Móia (c.p.) assinalou que certas condicionais factuais correlativas do PE podem ser parafraseáveis por estruturas com caso, ainda que talvez um pouco marginalmente e sem serem as formas mais naturais/frequentes:

i. a. Se está bom tempo, ficamos bem-dispostos.

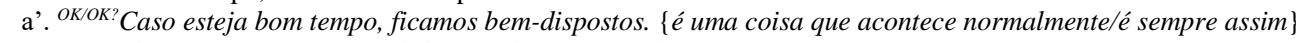

ii. a. Se o Rui estava doente a mãe telefonava-lhe todos os dias.

a'. ?Caso o Rui estivesse doente, a mãe telefonava-lhe todos os dias.

Mas, quanto a mim, a contraparte com caso remete a condicional para uma leitura episódica e não correlativa (*Antigamente/Normalmente caso o Rui estivesse doente, a mãe telefonava-lhe todos os dias.)
} 
advérbios do tipo nas manhãs ou afins (33a) ou com um ponto passado (33b), sendo a primeira frase agramatical e a segunda marginal, no PE.

(33) a. Caso não vá correr nas manhãs, estou com um grupo de amigos.

b. Antigamente, caso o Rui estivesse doente a mãe telefonava-lhe todos os dias.

Para terminar, pelo facto de, nas factuais de correlação de eventos, se poder usar ou o modo indicativo (Presente e o Pretérito Imperfeito) ou o conjuntivo (Futuro e o Pretérito Imperfeito), os dados apontam para que, no PM, a correspondência entre a factualidade e o tempo/modo não seja simples. Contribui para esta conclusão o facto de, no PM e ao contrário do PE, se usar, por vezes, o conjuntivo no lugar do indicativo, de que a frase os pais sempre tinham que dizer alguma coisa se as coisas não correr bem é um exemplo.

No PM, a alternância entre os modos indicativo e conjuntivo, nas factuais, é coerente com a ideia de que os seus falantes operam com competências múltiplas (cf. Gonçalves 2010 ou 2016) ou múltiplas proficiências em português (Justino 2015). Há formas e estruturas geradas pelas regras comuns às do PE (ou subvariedade educada do PM) e outras geradas pela própria gramática do PM (como é o exemplo do uso do Futuro do Conjuntivo nas factuais). Note-se ainda que o uso do Futuro do Conjuntivo, sobretudo nas condicionais de correlação de eventos passados, embora atestado nos dados, não é aceite como gramatical por todos os falantes da subvariedade culta do PM, como é o caso do investigador.

\subsection{Condicionais hipotéticas}

O PM assemelha-se ao PE no que diz respeito às hipotéticas, nas quais o valor de verdade do seu antecedente é desconhecido em $\mathrm{t}_{0}$, por aquelas poderem ocorrer quer no modo indicativo quer no conjuntivo. Tanto no PM como no PE, estas hipotéticas são parafraseáveis por estruturas com caso de valor hipotético, e podem ser modificadas por advérbios de referência futura, como, por exemplo, amanhã ou no futuro.

Apesar de o indicativo e o conjuntivo poderem ocorrer nas hipotéticas, note-se que o indicativo é preferencialmente usado no registo mais marcado, oral e informal quer no PM (34) quer no PE (35):

(34) Se acerto no totoloto, não modifico meu comportamento.

(35) Se te apanho perto da escola, dou-te uma sova a valer.

Mas condicionais como estas podem ser algo estranhas para um falante do PE à primeira leitura (Telmo Móia, c.p.), o que não parece acontecer no PM (Justino 2011). ${ }^{22}$ Aliás, no PM, é possível usar-se o modo indicativo em contextos em que no PE seria selecionado o modo conjuntivo: ${ }^{23}$

(36) a. Não vendo atacado, mas se conseguia ter um dinheiro de vender atacado, ia vender. (LFJ 51, Justino 2011) (PE = conseguisse)

b. Se alguém me pergunta se me disser que a educação baixou ainda terá que me focalizar onde parte portanto para dizer que baixou a qualidade da educação. ${ }^{24}$ (Corpus África) $(\mathrm{PE}=$ perguntasse)

\footnotetext{
${ }^{22}$ Note-se que, em certas variedades do PB, o uso do modo indicativo com valor hipotético é agramatical (Gomes 2008). Também para alguns falantes do PE é marginal o uso do indicativo com valor hipotético (Justino 2011) e não é referido em gramáticas do português que possa ser usado (cf. Mateus et al. 2003; Raposo et al. 2013, Bechara 1999, entre outros). Nalgumas gramáticas do inglês (cf. Quirk et al. 1985) e do espanhol (Montolío 1999) também não é referido que o indicativo possa ser usado.

${ }^{23}$ No PE, nas frases (36), a interpretação só poderia ser factual:

i. (Agora) não vendo atacado, mas (antes) sempre que conseguia dinheiro de vender atacado, ia vender.

ii. Quando alguém me pergunta se a educação baixou...

${ }^{24}$ Este exemplo mostra de facto a possibilidade de alternância conjuntivo/indicativo neste tipo de condicionais, que poderá significar, por outro lado, a falta de segurança por parte do falante do PM em relação ao modo verbal que é selecionado e, por outro, o conhecimento de duas regras gramaticais: uma do PM e a outra do PE/PM culto.
} 
Nestas frases, o Pretérito Imperfeito do Indicativo e o Presente são usados com valor temporal de futuro em relação a $t_{0}$. Para além disso, descrevem hipóteses em aberto que são distantes do que é esperado ou expectável num contexto conversacional, o que, do ponto de vista do PE, e tendo em conta a questão da acessibilidade epistémica e da fonte de ordenação (Kratzer 1991, e.o.), só é possível com o Pretérito Imperfeito do Conjuntivo (Marques 2001 e 2016). Assim, depreende-se que, no PM, mas não no PE, o indicativo e conjuntivo, que podem ocorrer em hipotéticas, podem estar em variação livre.

Por outro lado, no PE, mas não no PM, o Pretérito Mais-que-Perfeito do Conjuntivo pode ocorrer em condicionais hipotéticas (37). Em (37), o enunciador sugere de algum modo ao seu interlocutor que leia o artigo.

(37) Chegas a Coimbra às 10 horas. Se já tivesses lido o artigo, discutia-lo com eles. (Marques 2001: 325)

No PM, este tempo induz apenas a leitura contrafactual, indicando que a situação descrita não teve efetivamente lugar. Para se expressar, nas hipotéticas, um ato de fala diretivo recorre-se ao Imperfeito do Conjuntivo (38a) ou ao Presente do Indicativo (38b).

(38) a. Se apanhasses o metro já ali, chegarás a tempo. (PP)

b. A: O meu voo para Pemba é daqui a pouco e há falta de autocarros...

B: Mas se apanhas um táxi, chegas à hora de apanhar o avião. (PP)

No PE, o Pretérito Imperfeito do Conjuntivo também pode ser usado, mas não com o Futuro do Indicativo na oração principal, como pode acontecer no PM (38a). Já a frase (38b), com o indicativo (Presente) seria no PE marginal, porque não induz a leitura de sugestão/convite nem a de a hipótese de alguém apanhar um táxi, no futuro, estar aberta.

\subsection{Contrafactuais}

Como vimos na subsecção 3.3, as condicionais de interpretação contrafactual podem ser canónicas e não canónicas.

Relativamente às contrafactuais canónicas, tanto no PM como no PE, estas condicionais pressupõem que em $t_{0}$, o antecedente é dado como falso, sendo, por isso, possível acrescentar à proposição antecedente a sua negação (Brito 2003) ou parafraseá-las com estruturas com o caso (cf. Caso eu tivesse feito exame, mas não fiz, eu estou consciente que passava este curso).

No PM, às contrafactuais canónicas, está associado apenas o conjuntivo (Pretérito Imperfeito ou Pretérito Mais-Que-Perfeito). No PE, ao contrário do PM, para além do conjuntivo, pode-se usar o modo indicativo em contextos especialmente marcados, do ponto de vista de registo: o Presente (39a) e o Pretérito Perfeito Composto (39b) são frequentes no registo oral. O Pretérito Mais-que-Perfeito simples (39c) é raramente usado e, quando ocorre, é como uma forma supletiva do Pretérito Imperfeito do Conjuntivo.

(39) a. Se o Benfica faz o 0 x 2 no lance em que o Jonas vai isolado, o resultado do jogo teria sido diferente. (Justino 2016: 284)

b. Foi um salto excelente, pois ela não apanhou praticamente a tábua e se o tem feito melhor conseguiria cerca de 6,40m. par=ext26894-des-92b-1

c. Mas D. Pedro V, esse sim, se não morrera tão novo, poderia ter sido um grande estadista. par=ext1391943-soc-96a 
No PM, o Presente e o Pretérito Mais-que-Perfeito Composto, nas contrafactuais, são agramaticais. Ao contrário destas formas verbais, o Pretérito Mais-que-Perfeito simples é aceitável, de acordo com as minhas intuições, enquanto falante nativo, por ser equivalente ao Imperfeito do Conjuntivo (cf. Se Samora Machel não morrera em 1986, o país seria diferente. (PP)). Na frase (40) do PM, atesta-se o uso do Pretérito Maisque-Perfeito simples com valor equivalente ao Pretérito Imperfeito do Conjuntivo contrafactual.

(40) Crescia com resoluta obsessão. Progressivo como se houvera alvo. (CRPC)

No PM, mas não no PE, por os falantes operarem com competências múltiplas em português (Gonçalves 2010, 2016, Justino 2015), observa-se, por um lado, que há falantes que podem selecionar o indicativo em vez do conjuntivo, para marcar a contrafactualidade:

(41) Nós estaríamos muito felizes se podemos dispor de infra-estruturas que pudéssemos apenas reformar, disse Chissano. (CRPC)

Por outro lado, a contrafactualidade é expressa por fosse (que) + Pretérito Imperfeito do Indicativo do verbo principal (42), como consequência da retenção, na gramática adulta/final, de uma construção recorrente no estágio inicial da aquisição do PM.

(42) Aquele homem é um fugista. Se não fosse era um fugista, ele havia de parar aqui. (CRPC)

Quanto às contrafactuais não canónicas (43), por não serem coordenáveis com adversativas de polaridade inversa nem parafraseáveis com recurso a caso (44), ao contrário das de sentido irónico (44b), as enfáticas (44a) podem ser estruturas particulares do PM. ${ }^{25}$

(43) a. Se Wazimbo não fosse cantor, seria cantor. par=2

b. Se tu és santo, eu sou o Papa. (PP)

(44) a. *Se/Caso Wazimbo não fosse cantor, mas é, seria cantor.

b. *Caso tu sejas santo, mas não és, eu sou o Papa.

Nas enfáticas, para além de não existir uma relação de sentido causa efeito entre as duas orações (cf. *Se Wazimbo não fosse cantor, então seria cantor.), usa-se, no consequente, uma proposição que é contraditória do antecedente, o que funciona como uma estratégia de reforço da leitura contrafactual. Por exemplo, (43a) quererá dizer que Wazimbo não seria outra coisa senão cantor.

\section{Considerações finais}

As semelhanças e diferenças entre o PM e o PE, relativamente à distribuição dos tempos/modos verbais nas condicionais de se, são apresentadas no quadro em anexo (Anexo 1). De um modo geral, esses resultados mostram que não existem grandes diferenças entre o PM e o PE: há três classes semânticas (factuais, hipotéticas e contrafactuais) e a correspondência entre elas e o uso dos tempos/modos verbais é não

\footnotetext{
${ }^{25}$ Este tipo de contrafactuais não é referido na literatura consultada nem ocorre nos dados de corpora do PE analisados por Justino (em curso).
} 
biunívoca, dado que cada uma das classes pode ser marcada quer pelo modo indicativo quer pelo modo conjuntivo.

No entanto, encontramos algumas diferenças, entre o PM e o PE, em contextos em que, no PE, se usam de forma mais marcada tempos/modos verbais nas hipotéticas ou contrafactuais. São exemplos desta constatação o facto de, no PE, mas não no PM, se usar o Pretérito Mais-que-Perfeito do Conjuntivo com valor hipotético, facto não referido nas gramáticas do $\mathrm{PE}$, em condicionais que envolvem uma espécie de ato de fala diretivo indireto. Por sua vez, o PM exprime este valor usando, para além do Pretérito Imperfeito do Conjuntivo, o Presente do Indicativo. Nas contrafactuais canónicas, no PE, usa-se também o Presente do Indicativo, com valor modal contrafactual, descrevendo uma ação completamente realizada (perfectiva) (Justino 2016), e o Pretérito Perfeito Composto do Indicativo, com o valor equivalente ao Imperfeito do Conjuntivo contrafactual. No PM, isto é marginal, porque a estes tempos do indicativo não são associados estes valores modais mais marcados. No PE, o modo indicativo (sobretudo o Presente), em hipotéticas, é usado no discurso oral e em contextos informais, e nem sempre pode ser natural para um falante do PE (cf. Justino 2011). No PM, pelo contrário, pode ocorrer tanto no registo oral como no escrito e é sempre gramatical, confirmando o trabalho de Justino (2011).

Além das diferenças acima referidas, sobressaem diferenças que resultam da ambiguidade do input do PE. No PE, apesar de indicativo e conjuntivo não estarem em variação livre, os tempos do indicativo e (alguns tempos) do conjuntivo podem ocorrer associados às três classes semânticas. No PM, observámos que há variação/alternância livre entre o Indicativo e o Conjuntivo nas condicionais hipotéticas e factuais. Nas hipotéticas, há uma tendência para a selecão do indicativo em contextos em que, no PE, o conjuntivo é que seria obrigatório. Está, neste caso, por exemplo, o uso do Imperfeito e do Presente do Indicativo em vez do Pretérito Imperfeito do Conjuntivo. Nas factuais correlativas de eventos passados, usa-se o conjuntivo em contextos em que, no PE, o indicativo é que seria obrigatório (cf., por exemplo, o uso do Futuro do Conjuntivo no lugar do Pretérito Imperfeito do Indicativo).

Por último, refira-se que o PM, enquanto adquirido como uma L2 ou como L1, se distingue claramente do PE no que diz respeito (i) ao uso do Futuro do Conjuntivo nas condicionais factuais, (ii) à expressão da contrafactualidade através de fosse (que) + Pretérito Imperfeito do Indicativo do verbo principal, (iii) à expressão da contrafactualidade através da enfâse - repetição do mesmo verbo da oração principal na matriz, e (iv) à possibilidade de o conector caso poder encabeçar quaisquer condicionais factuais correlativas de eventos.

\section{Referências}

Bechara, Evanildo (1999) Moderna gramática portuguesa. Rio de Janeiro: Lucerna.

Brito, Ana Maria (2003) Subordinação adverbial. In. Maria Helena Mateus et al. (orgs.) Gramática do Português. Lisboa: Caminho, pp. 695-728.

Chimbutane, Feliciano (2012) Panorama linguístico de Moçambique: Análise dos dados do III Recenseamento Geral da População e Habitação de 2007. Maputo, Moçambique: INE.

von Fintel, Kai (2012) Subjunctive Conditionals. In Gillian Russell \& Delia Graff Fara (eds.) The Routledge Companion to Philosophy of Language. New York: Routledge, pp. 466-477.

Gonçalves, Perpétua (2010) A Génese do Português de Moçambique. Lisboa: Imprensa Nacional/Casa da Moeda. Gonçalves, Perpétua (2013) O Português em África. In Eduardo Paiva Raposo et al. (eds.) Gramática do Português. Lisboa: Fundação Calouste Gulbenkian, pp. 157-168.

Gonçalves, Perpétua (2016) Competência Múltiplas das Novas gerações de Falantes em Moçambique: Desafios para a Teoria e para a Planificação Linguística. In Teixeira e Silva Roberval (org.) Contextos de Formação 
de Novas Gerações de Falantes do Português no Mundo: Perspectivas em Política, História, Língua e Literatura. Escola Superior de Educação de Santarém: Universidade de Macau, pp. 97-112.

Gomes, Gilberto (2008) Three Types of Conditionals and Their Verb Forms in English and Portuguese. Cognitive Linguistics 19 (2), pp. 219-240.

Iatridou, Sabine (1991) Topics in Conditionals. PhD dissertation, Cambridge, MIT.

Justino, Víctor (2011) A Distribuição e a Expressão Gramatical do Futuro do Conjuntivo no Português de Moçambique. Dissertação de mestrado, Lisboa, Universidade de Lisboa.

Justino, Víctor (2015) Concordância Verbal em Número: Da Descrição Linguística à Avaliação no Contexto de Ensino-Aprendizagem. In Mónica Bastos, José Marques, Ana Monteiro e Conceição Siopa (orgs) Ensinar a língua portuguesa em Moçambique: Desafios, Possibilidades e Constrangimentos. Textos Selecionados das VII Jornadas da Língua Portuguesa. Porto: Porto Editora, pp. 166-186.

Justino, Víctor (2016) Os Valores Semânticos das Condicionais e sua Relação com os Tempos e Modos Verbais. Revista da Associação Portuguesa de Linguística 2, pp. 265-293.

Justino, Víctor (em curso). As Condicionais de 'se' no Português de Moçambique e no Português Europeu. Tese de doutoramento. Universidade de Lisboa.

Karttunen, Lauri \& Stanley Peters (1979). Conventional Implicature. In Choon-Kyu David Dinneen (ed.) Syntax and Semantics 11: Presupposition, New York Academic Press, pp. 1-56.

Kratzer, Angelika (1991) Modality. In Arnim von Stechow \& D. Wunderlich (orgs.) Semantics. Berlim: Walter de Gruyter, pp. 639-650.

Lakoff, George (1970) Linguistics and Natural Logic. Synthese 22 (1/2), pp. 151-271.

Larsen-Freeman, Dianne \& Long, Michael (1991) An introduction to second language acquisition research. Harlow: Addison Wesley Longman Ltd.

Lightfood, David (2006) How new Languages Emerge. Cambridge: Cambridge University Press.

Lobo, Maria (2013) Subordinação Adverbial. In Eduardo Paiva Raposo et al. (eds.) Gramática do Português. Lisboa: Fundação Calouste Gulbenkian, pp. 1879-2057.

Lopes, Cristina Macário (2009) Contributos para o Estudo de Construções Condicionais não Canónicas no PEC. Diacrítica 23 (1), pp.149-170.

Marques, Rui (2001) O modo em condicionais contrafactuais e hipotéticas. Textos Selecionados do XVI Encontro da Associação Portuguesa de Linguística. Lisboa: APL, pp. 325-335

Marques, Rui (2016) O Modo Conjuntivo. In Ana Maria Martins e Ernestina Carrilho (eds.) Manual de Linguística Portuguesa. Gruyter, pp. 610-635.

Mateus, Maria Helena et al. (2003) Gramática do Português. Lisboa: Caminho.

Mönnink, Inge de (1999) Combining Corpus and Experimental Data. Internacional Journal of Corpus Linguistics, 4 (1), pp. 77-111.

Montolío, Estrella (1999) Las constructiones condicionales. In Ignacio Bosque \& Violeta Demonte (eds.) Gramática Descriptiva de la Lengua Española. Madrid: Espasa, pp. 3643-3737.

Norris, Robert (2003) How do we overcome the Difficulties of Teaching Conditionals?. In Bulletin of Fukuoka International University 9, pp. 39-50.

Quirk, Randolph et al. (1985) A Comprehensive Grammar of the English Language. London: Longman. Raposo, Eduardo Paiva et al. (2013) Gramática do Português. Lisboa: Fundação Calouste Gulbenkian. Reis, Sílvia Lopes (2006) Estudo de Inglês para Turismo: Recurso à Linguística de Corpus.

Dissertação de mestrado, Universidade de Lisboa. 
ANEXO I: Tempo e Modo nas condicionais factuais, hipotéticas e contrafactuais do PM e do PE

\begin{tabular}{|c|c|c|c|c|}
\hline \multicolumn{2}{|c|}{ Classes Semânticos/Subclasses } & \multicolumn{3}{|c|}{ Tempos e modos verbais } \\
\hline & & Antecedente $(P)$ & Consequente $(Q)$ & Obs \\
\hline \multirow{13}{*}{ Factuais } & Genéricas & Presente genérico & Presente genérico & $\mathrm{PM} / \mathrm{PE}$ \\
\hline & \multirow{6}{*}{$\begin{array}{l}\text { Correlativas de } \\
\text { eventos/situações }\end{array}$} & \multirow[t]{2}{*}{ Presente habitual } & Presente habitual/Futuro & $\mathrm{PM} / \mathrm{PE}$ \\
\hline & & & Pretérito Perfeito Composto & $\mathrm{PM} / \mathrm{PE}$ \\
\hline & & Imperfeito habitual & Imperfeito habitual & $\mathrm{PM} / \mathrm{PE}$ \\
\hline & & Imperfeito do Conjuntivo & Imperfeito habitual & $\mathrm{PM} / \mathrm{PE}$ \\
\hline & & Futuro do Conjuntivo habitual & Presente habitual & Só PM \\
\hline & & Futuro do Conjuntivo (= Imperf.) & Imperfeito habitual & Só PM \\
\hline & \multirow{6}{*}{ Episódicas } & Presente do Indicativo & Presente do Indicativo/Futuro & $\mathrm{PM} / \mathrm{PE}$ \\
\hline & & Pretérito Perfeito do Indicativo & Pretérito/Presente/Futuro Ind. & $\mathrm{PM} / \mathrm{PE}$ \\
\hline & & Pretérito Perfeito Composto Ind. & Presente/Futuro do Indicat. & Só PE \\
\hline & & Imperfeito do Indicativo & Imperfeito/Futuro do Indicat. & $\mathrm{PM} / \mathrm{PE}$ \\
\hline & & Futuro do Indicativo & Presente/Futuro do Indicat. & Só PE \\
\hline & & Pretérito M-q-Perfeito do Ind. & Modo Condicional & Só PE \\
\hline \multirow{15}{*}{ Hipotéticas } & \multirow{14}{*}{ Episódicas } & Futuro do Conjuntivo & Presente/Futuro/Imperativo & $\mathrm{PM} / \mathrm{PE}$ \\
\hline & & Futuro do Conjuntivo (= Imperf.) & Condicional & Só PM \\
\hline & & Futuro Composto do Conjuntivo & Presente/Futuro do Indicativo & $\mathrm{PM} / \mathrm{PE}$ \\
\hline & & \multirow[t]{2}{*}{ Imperfeito do Conjuntivo } & Imperf. do Indic/ Condicional & $\mathrm{PM} / \mathrm{PE}$ \\
\hline & & & Futuro/Presente do Indicat. ${ }^{1}$ & Só PM \\
\hline & & Pretérito Mais-q-Perf do Conj ${ }^{2}$ & Imperfeito do Indicativo & Só PE \\
\hline & & Presente do Indicativo & Presente/Futuro do Indicativo & $\mathrm{PM} / \mathrm{PE}$ \\
\hline & & Presente do Indicativo $^{3}$ & Presente do Indicativo & Só PM \\
\hline & & Pretérito Perfeito do Indicativo & Pretérito Presente/Futuro Ind. & $\mathrm{PE} / \mathrm{PM}$ \\
\hline & & Imperfeito do Indicativo & Imperfeito do Indicativo & $\mathrm{PM} / \mathrm{PE}$ \\
\hline & & Imperfeito do Ind. (= Imper. Conj.) & Imperfeito do Ind./Condiconal & Só PM \\
\hline & & Pretérito M-q-Perfeito do Ind. & Imperfeito/Pretérito Perfeito & $\mathrm{PM} / \mathrm{PE}$ \\
\hline & & Pretérito Perfeito Composto & Presente/Futuro do Indicativo & Só PE \\
\hline & & Modo Condicional & Modo Condicional & Só PE \\
\hline & Correlativas & Futuro do Conjuntivo & Futuro do Indicativo & $\mathrm{PM} / \mathrm{PE}$ \\
\hline \multirow{11}{*}{ Contrafactuais } & \multirow[t]{5}{*}{ Comuns } & Pretérito M-Q-P do Conjuntivo & $\begin{array}{l}\text { Imperfeito/Condicional } \\
\text { Simp/composto }\end{array}$ & $\mathrm{PM} / \mathrm{PE}$ \\
\hline & & Pretérito Imperfeito do Conjuntivo & $\begin{array}{l}\text { Imperfeito/Condicional/ } \\
\text { Pretérito M-Q-P Composto }\end{array}$ & $\mathrm{PM} / \mathrm{PE}$ \\
\hline & & Presente do Indicativo & Imperfeito & Só PE \\
\hline & & Pretérito Perf. Composto do Ind. & Imperfeito/Condicional & Só PE \\
\hline & & Pretérito M-Q-Perfeito Simples & Imperfeito/Condicional & $\mathrm{PM} / \mathrm{PE}$ \\
\hline & Enfáticas & Imperfeito do Conjuntivo & Imperfeito do Indicativo & Só PM \\
\hline & \multirow{5}{*}{ Irónicas } & Presente do Indicativo & Presente do Indicativo & $\mathrm{PM} / \mathrm{PE}$ \\
\hline & & Pretérito Perfeito do Indicativo & Presente do Indicativo & $\mathrm{PM} / \mathrm{PE}$ \\
\hline & & Pretérito Imperfeito do Indicativo & Presente do Indicativo & $\mathrm{PM} / \mathrm{PE}$ \\
\hline & & Futuro do Conjuntivo & Presente do Indicativo & $\mathrm{PM} / \mathrm{PE}$ \\
\hline & & $\begin{array}{l}\text { Pretérito Imperfeito do Indicativo } \\
\text { Pretérito (Imperfeito ou M-Q-P do } \\
\text { Conjuntivo) }\end{array}$ & $\begin{array}{l}\text { Imperfeito do Indicativo } \\
\text { Imperfeito do Indicativo }\end{array}$ & $\begin{array}{l}\text { Só PE } \\
\text { Só PE }\end{array}$ \\
\hline
\end{tabular}

\footnotetext{
${ }^{1}$ Com um valor pragmático afim (convite/sugestão): Se apanhasses o metro já ali, chegarás/chegas a tempo.

${ }^{2}$ Idem a nota anterior.

${ }^{3}$ Nos contextos em que tem um valor afim, sugestão/convite: Se apanhas o metro já ali, chegas a tempo.
} 


\section{ANEXO II}

\section{I - TAREFAS DE PRODUÇÃO PROVOCADA - EXEMPLOS ILUSTRATIVOS}

TAREFA I - Forme todas as frases possíveis usando o verbo entre parênteses para preencher os espaços em branco, conforme os exemplos. Note que o número de frases a construir em cada caso pode variar entre uma e quatro. Construa só as frases que lhe parecem naturais e que poderia usar espontaneamente ou na oralidade ou na escrita.

Exemplo:
a) Se a lua __ (ser) uma estrela, ___ (ter) uma luz própria.
Se a lua fosse uma estrela, teria uma luz própria.
Se a lua for uma estrela, terá uma luz própria.
Se a lua é uma estrela, tem luz própria.
Se a lua era uma estrela, tinha luz própria.

1. Normalmente, se ele me (dar) conselhos, eu (aceitar).

2. Se os homens (ter) asas, eles (ser) capazes de voar

3. Se a Maria (ter) bordado a toalha, possivelmente, não (precisar) de comprar outra.

TAREFA II - Nas frases abaixo, preencha os espaços em branco com o verbo entre parênteses. Siga os exemplos e tenha em atenção que pode construir mais do que uma frase, mas não é necessário que o faça.

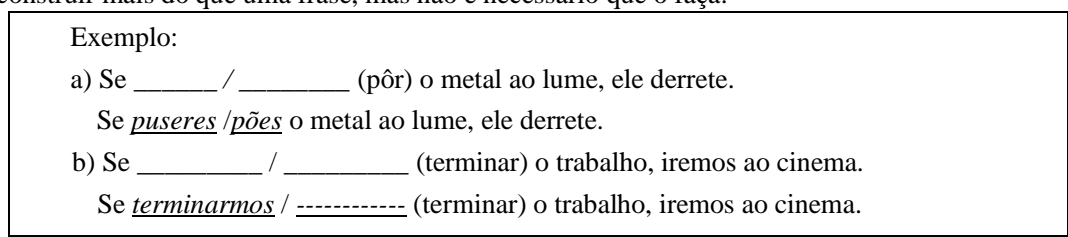

1. Já perdemos o nosso avião. Mas se nós (apanhar) táxi, chegávamos a tempo

2. Todos os humanos são mortais. Logo, se tu 1 (ser) humano, então és mortal.

3. Se tu (ser), eu sou a miss universo.

\section{TESTE DE JUÍZO DE GRAMATICALIDADE}

Leia atentamente as frases (1) a (20).

1) Coloque, no início de cada uma das frases, os seguintes símbolos, de acordo com as instruções fornecidas:

a) Coloque '*' no início das frases que considerar incorretas.

b) Coloque 'ok' no início das frases que considerar corretas

c) Coloque '?' no início das frases de cuja correção duvida.

2) Apresente uma alternativa para as frases que marcou com '*' ou com '?'.

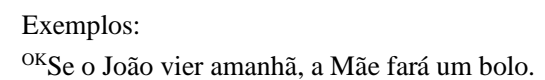

?/*Se ele for a viajar no próximo mês, então devíamos publicar o seu livro neste mês Se ele vai viajar no próximo mês, então devíamos publicar o seu livro neste mês

1. Moçambique foi sempre assim: se chovesse muito, as ruas ficavam alagadas.

2. Se o Zé tem ido às aulas, não chumbava no primeiro ano.

3. Ele chegou ontem de Londres. Se eu sabia disso, ia saudá-lo à chegada.

№ 4 - 09/2018 | 98-116 | https://doi.org/10.26334/2183-9077/rapln4ano2018a35 